\title{
Evapotranspiration Trend and Its Relationship with Precipitation over the Loess Plateau during the Last Three Decades
}

\author{
Zesu Yang, ${ }^{1,2}$ Qiang Zhang, ${ }^{2}$ and Xiaocui Hao ${ }^{3}$ \\ ${ }^{1}$ Plateau Atmospheric and Environment Key Laboratory of Sichuan Province, College of Atmospheric Sciences, \\ Chengdu University of Information Technology, Chengdu 610225, China \\ ${ }^{2}$ Institute of Arid Meteorology, China Meteorological Administration, Key Laboratory of Arid Climatic Change and Reducing Disaster \\ of Gansu Province, Key Open Laboratory of Arid Climatic Change and Disaster Reduction of CMA, Lanzhou 730020, China \\ ${ }^{3}$ Northwest Regional Climate Center, Lanzhou 730020, China
}

Correspondence should be addressed to Zesu Yang; zesuyang@outlook.com

Received 25 December 2015; Accepted 5 June 2016

Academic Editor: Gang Liu

Copyright (c) 2016 Zesu Yang et al. This is an open access article distributed under the Creative Commons Attribution License, which permits unrestricted use, distribution, and reproduction in any medium, provided the original work is properly cited.

\begin{abstract}
There have been few studies conducted on the changes in actual ET over the Loess Plateau, due to the lack of reliable ET data. Based on ET data simulated by the Community Land Model, the present study analyzed the changes in ET over the Loess Plateau. The results showed the domain-average ET to have decreased in the past 31 years, at a rate of $0.78 \mathrm{~mm}_{\text {year }}{ }^{-1}$. ET fluctuated much more strongly in the 1990s than in the 1980s and 2000s, and, apart from in autumn, ET decreased in all seasons. In particular, ET in summer comprised about half of the annual ET trend and had the sharpest trend, dominating the interannual decline. ET also decreased more sharply in the semiarid than semihumid regions. The declining trend of ET was attributed to declining precipitation and air humidity. Locally, the ET trend was closely related to local mean annual precipitation: in areas with precipitation less than $400 \mathrm{~mm}$, ET showed a decreasing trend; in areas with precipitation larger than $600 \mathrm{~mm}$, ET showed an increasing trend; and in areas with precipitation in the range of $400-600 \mathrm{~mm}$ could be classified as a transitional zone.
\end{abstract}

\section{Introduction}

Evapotranspiration (ET) - the process of transferring water from the land surface to the atmosphere-is the link between the global water cycle, energy cycle, and carbon cycle and is of critical importance for agriculture, hydrology, ecology, and the climate system $[1,2]$. Changes in ET will also change the energy partitioning between sensible and latent heat, altering atmospheric dynamics and influencing weather and climate [3]. A detailed understanding of changes in global and regional ET could in turn help us to understand the global water cycle and its role in the climate system.

Against the background of increased air temperature associated with global warming, the atmosphere is able to hold more water, leading to increases in the fluxes of water globally via the water cycle [4]. Usually, the evidence put forward to support this conclusion involves increases in precipitation and runoff, but not ET trends, because the latter are very hard to observe. Potential ET - the upper limit of ET, indicative of evaporative ability-is relatively easy to obtain, plus, there are also some other variables that can represent evaporative ability, including pan evaporation and reference ET. Many studies have investigated trends of pan evaporation, potential ET, and reference ET regionally or globally. These trends, however, are not consistent among different regions of the globe. Theoretically, global warming would increase pan evaporation, but there are only a few regions where the evidence supports this inference, including Israel [5], northeast Brazil [6], Australia [7], and China [8]. In fact, most regions indicate an opposite conclusion, that is, a decrease in pan evaporation, for example, America $[9,10]$, Canada [11], Greece [12], India [13], Thailand [14], Japan [15], China $[16,17]$, Australia [18], and New Zealand [19]. Likewise, two studies on potential ET have also concluded opposite trends 


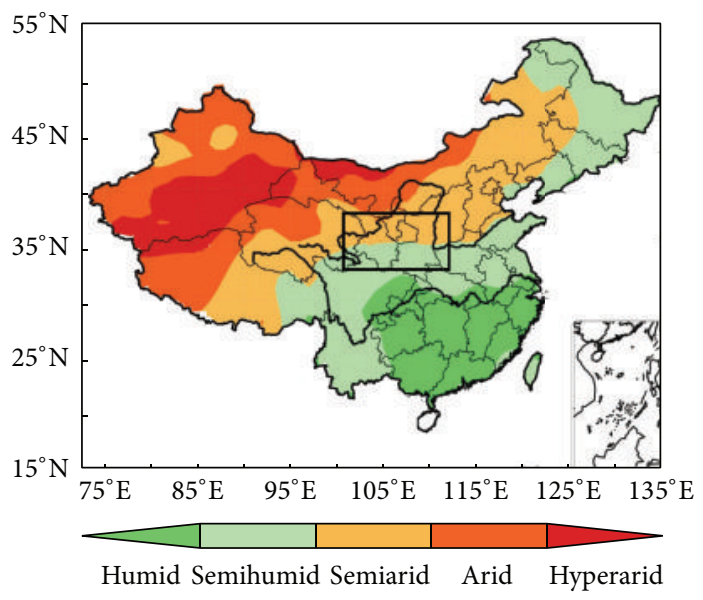

(a)

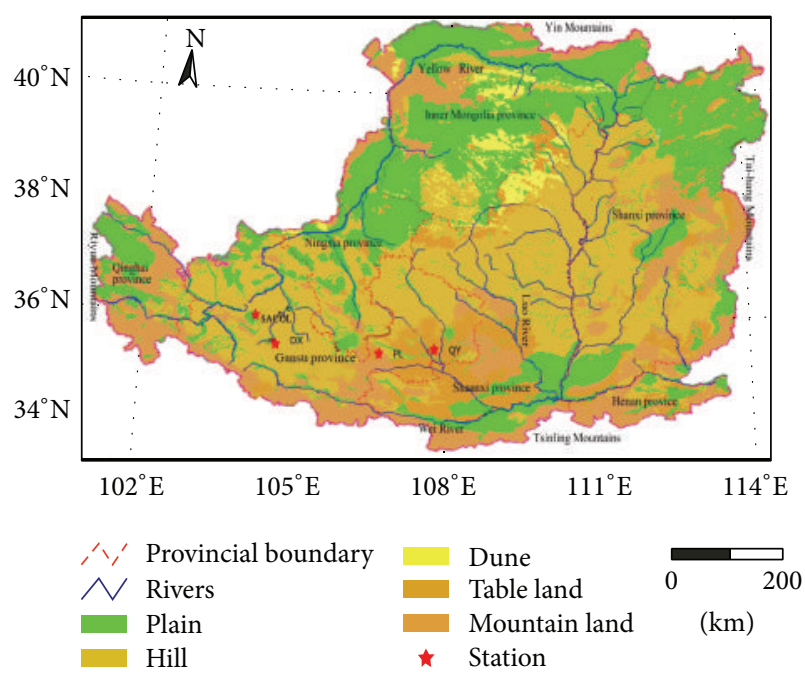

(b)

FIGURE 1: The (a) location and climate of the Loess Plateau (black line) and (b) its land cover and the locations of the ET observatories (red stars).

in different regions $[20,21]$. Actual ET is closely related to potential ET or pan evaporation, but the implication of the trend in pan evaporation for the trend in actual ET has long been disputed. Some scientists argue that the declining trend in pan evaporation indicates a declining trend in actual ET. Others suggest that a complementary relationship between potential and actual ET exists, with declining ET meaning an increase in actual ET. Recent studies have shown that these two relationships are correct under certain conditions [17, 22, 23]. Apparently, the positive relationship is satisfied under conditions of sufficient water, while the complementary relationship is satisfied under water-limited conditions.

Potential ET is decreasing in most regions of China; however, pan evaporation and potential ET are increasing in the Loess Plateau $[24,25]$. Since the trend of pan evaporation and potential ET only provides us with a clue for the possible trend of actual ET, and because potential ET and pan evaporation have a special trend in the Loess Plateau compared to other regions of China, our goal in the present study was to probe the characteristics of actual ET by examining whether the trend in actual ET in the Loess Plateau also shows distinct regional features, like potential ET. Besides, because the Loess Plateau is situated in the boundary zones influenced by the Asian summer monsoon, precipitation demonstrates considerable spatial variation [26], which in turn causes spatial variation in land surface hydrothermal processes. It is therefore also of interest to investigate the relationship between ET trends and precipitation on the local scale.

For a long time, research on actual ET has been limited by a lack of reliable ET data [1]. In recent years, however, the Global Land Data Assimilation System (GLDAS) has become an important dataset for global change and water cycle research $[27,28]$. Employing the Community Land Model (CLM), GLDAS produces land surface ET data on the global scale, and its land surface variables are reported to be highly consistent with observations in the Loess Plateau [27]. In this study, we first validated the ET products of GLDAS using ET data observed by an eddy covariance (EC) system at four land surface observatories in the Loess Plateau. Then, on the basis of GLDAS ET data, we analyzed the trends of ET, and their reasons, over the Loess Plateau. In addition, the relationship between ET trends and mean annual precipitation locally was also analyzed.

\section{Study Area and Data}

2.1. Study Area. The Loess Plateau-located to the north of the Yin Mountains, south of the Tsinling Mountains, east of the Tai-hang Mountains, and west of the Riyue Mountainsis a highly unique land type with special ecosystems. The average altitude is approximately $1000 \mathrm{~m}$ above sea level, increasing from southeast to northwest. The most common topography is gully and hilly terrain, and the specific geomorphology is shown in Figure 1. The Loess Plateau is located in the boundary zone of the Asian summer monsoon. It is a transitional region from the humid climate in the southeast, under the influence of the summer monsoon, to the arid climate in the northwest (Figure 1, rectangle), and thus can be divided into two parts, that is, the semiarid zone in the northwest and the semihumid zone in the southeast [29] (Figure 1). The annual average rainfall is approximately $466 \mathrm{~mm}$, with $700 \mathrm{~mm}$ in the southeastern regions and $120 \mathrm{~mm}$ in the northwestern regions. The mean annual temperature ranges from $4^{\circ} \mathrm{C}$ to $12^{\circ} \mathrm{C}$. The main soil type is loess, which has a weak ability to resist wind and soil erosion.

\subsection{Data and Data Processing}

2.2.1. Simulated ET Data. The simulated ET data were downloaded from GLDAS. As the main dynamic framework, the land surface model is the key part of GLDAS. The forcing 
TABLE 1: Information on the validation sites.

\begin{tabular}{|c|c|c|c|c|c|c|}
\hline Site & Location & Elevation $(\mathrm{m})$ & Land cover & Precipitation $(\mathrm{mm})$ & Temperature $\left({ }^{\circ} \mathrm{C}\right)$ & Climate \\
\hline Dingxi & $35^{\circ} 35^{\prime} \mathrm{N}, 104^{\circ} 37^{\prime} \mathrm{E}$ & 1896 & Cropland & 386 & 6.7 & Semiarid \\
\hline SACOL & $35^{\circ} 57^{\prime} \mathrm{N}, 104^{\circ} 08^{\prime} \mathrm{E}$ & 1966 & Grassland & 381.8 & 6.7 & Semiarid \\
\hline Qingyang & $35^{\circ} 41^{\prime} \mathrm{N}, 107^{\circ} 51^{\prime} \mathrm{E}$ & 1280 & Cropland & 562 & 8.8 & Semihumid \\
\hline Pingliang & $35^{\circ} 34^{\prime} \mathrm{N}, 106^{\circ} 35^{\prime} \mathrm{E}$ & 1480 & Cropland & 511.2 & 8.7 & Semihumid \\
\hline
\end{tabular}

data were provided by the Global Data Assimilation System of the National Centers for Environmental Prediction and the Data Assimilation System of the Goddard Space Flight Center. This study used monthly ET data simulated by the Community Land Model (CLM), with a horizontal resolution of $1^{\circ} \times 1^{\circ}$, from January 1982 to December 2013. A rectangular region of $\left(34^{\circ}-41^{\circ} \mathrm{N}, 101^{\circ}-114^{\circ} \mathrm{E}\right)$, including the Loess Plateau, was selected. The simulation data can be obtained directly from the website of GLDAS: http://disc.sci.gsfc.nasa.gov/hydrology/data-holdings.

CLM was developed from three land models: the Land Surface Model of the National Center for Atmospheric Research; the land model of the Institute of Atmospheric Physics, Chinese Academy of Sciences land model; and the Biosphere-Atmosphere Transfer Scheme. As such, it has the best features of these three land models and offers improvements regarding certain parameterization schemes. CLM was developed as the land surface module of the Community Earth System Model and the Community Atmosphere Model. Land biogeophysical and hydrological processes are the main processes simulated by CLM, including (1) vegetation composition, structure, and phenology; (2) absorption, reflection, and transmittance of solar radiation; (3) absorption and emission of longwave radiation; (4) momentum, sensible heat (ground and canopy), and latent heat (ground evaporation, canopy evaporation, and transpiration) fluxes; (5) heat transfer in the soil and snow, including phase changes; (6) canopy hydrology (interception, throughfall, and drip); (7) snow hydrology (snow accumulation and melt, compaction, and water transfer between snow layers); (8) soil hydrology (surface runoff, infiltration, subsurface drainage, and redistribution of water within the column); (9) stomatal physiology and photosynthesis. When simulating latent heat flux, the equations used for the ET calculation are [30]

$$
\begin{aligned}
E & =E_{v}+E_{g}, \\
E_{v} & =-\rho_{\text {atm }} \frac{\left(q_{s}-q_{\text {sat }} T_{v}\right)}{r_{\text {total }}}, \\
E_{g} & =-\rho_{\text {atm }} \frac{\left(q_{s}-q_{g}\right)}{r_{\text {aw }}^{\prime}}, \\
\frac{1}{r_{\text {total }}} & =\frac{L^{\text {sun }}}{r_{b}+r_{s}^{\text {sun }}}+\frac{L^{\text {sha }}}{r_{b}+r_{s}^{\text {sha }}}, \\
r_{b} & =\frac{1}{C_{v}}\left(\frac{U_{*}}{d_{\text {leaf }}}\right)^{-1 / 2},
\end{aligned}
$$

$$
\begin{aligned}
& r_{\mathrm{aw}}^{\prime}=\frac{1}{C_{s} u^{*}}, \\
& \frac{1}{r_{s}}=m \frac{A}{c_{s}} \frac{e_{s}}{e_{i}} P_{\mathrm{atm}}+b,
\end{aligned}
$$

where $q_{s}$ is the specific humidity of the canopy roof; $q_{g}$ is the specific humidity of the land surface; $q_{\text {sat }}{ }^{T_{v}}$ is the humidity of the canopy; $E_{v}$ is the vegetation transpiration; $E_{g}$ is the evaporation; $r_{\text {total }}$ is the total resistance to water vapor transfer from the canopy to the canopy air, including the leaf boundary resistance $r_{b}$ and stomatal resistance $r_{s} ; r_{\mathrm{aw}}^{\prime}$ is the aerodynamic resistance to water vapor transfer between the ground and the canopy air; $A$ is the photosynthesis; $m$ is a parameter associated with atmospheric conditions and plant type; $b$ is an empirical parameter; $u^{*}$ is friction velocity; $C_{s}$ is the turbulent transfer coefficient; $L^{\text {sun }}$ and $L^{\text {sha }}$ are the sunlit and shaded leaf area indices, respectively; $r_{s}^{\text {sun }}$ and $r_{s}^{\text {sha }}$ are the sunlit and shaded stomatal conductance, which can use the average absorbed photosynthetically active radiation for sunlit and shaded leaves, respectively; $c_{s}$ is the $\mathrm{CO}_{2}$ concentration at the leaf surface; $e_{s}$ is the vapor pressure at the leaf surface; $e_{i}$ is the saturation vapor pressure inside the leaf at the vegetation temperature; and $P_{\text {atm }}$ is the atmospheric pressure.

2.2.2. In Situ ET Data. ET was measured by an EC (eddy covariance) system at four land surface observatories in the Loess Plateau (see Figure 1 and Table 1). The EC system included a three-dimensional ultrasonic anemometer (CSAT-3, Campbell, USA) and a quick response infrared analyzer (Li7500, Li-Cor, USA) and was set at a height of $2.5 \mathrm{~m}$. The sampling frequency was $10 \mathrm{~Hz}$. Latent heat flux was calculated by

$$
\mathrm{LE}=\rho \lambda \overline{\omega^{\prime} q^{\prime}},
$$

where LE is latent heat flux, $\rho$ is air density, $\lambda$ is the latent heat of vaporization, and $\omega^{\prime}$ and $q^{\prime}$ are the fluctuations around the averages of vertical wind speed and specific humidity, respectively.

The data from the EC system were processed as follows [31]: first, quality control and gap filling: (i) half-hourly data from periods of sensor malfunction were deleted; (ii) halfhourly data within $1 \mathrm{~h}$ before or after rainfall were deleted; (iii) half-hourly data $\left(x_{i}\right)$ were deleted when $x_{i} \geq(+4 \delta)$ or $x_{i} \leq(-4 \delta)$, where $\delta$ is standard deviation. On average, the datasets contained $18.9 \%$ missing or rejected ET data. Missing data were filled using a look-up table method [32]. For each 
TABLE 2: Correlation statistics between predicted ET and observations at four sites in the Loess Plateau.

\begin{tabular}{lcccc}
\hline Site & Fitting coefficient & Correlation coefficient & Root-mean-square error (mm) & Relative error $(\%)$ \\
\hline SACL & 0.969 & 0.94 & 7.9 & 18.1 \\
Dingxi & 0.834 & 0.87 & 9.4 & 21.5 \\
Pingliang & 0.918 & 0.95 & 8.4 & 19.3 \\
Qingyang & 0.935 & 0.96 & 6.8 & 22.4 \\
\hline
\end{tabular}

Correlation coefficients passed the significance test at all sites $(P<0.01)$.

study site, tables were created based on the four seasons. For each season, ET was classified by $20 R_{n}$-classes $\times 35 \operatorname{VPD}\left(R_{n}\right.$, net radiation; VPD, vapor pressure deficit). $R_{n}$ consisted of $50 \mathrm{~W} \mathrm{~m}^{-2}$ intervals from -200 to $800 \mathrm{~W} \mathrm{~m}^{-2}$. Similarly, VPD consisted of $0.15 \mathrm{kPa}$ intervals ranging from 0 to 5.1 , with a separate class for VPD $=0$. Gaps with no mean assigned in the look-up tables were interpolated linearly. Tables of ET means and standard deviation were produced by the procedure. Thus, we filled the missing data by referring to the synchronous $R_{n}$ and VPD. Then, half-hourly LE data were transformed to half-hourly ET. Finally, half-hourly ET data were aggregated to monthly ET.

Since energy disclosure is an inevitable problem for EC [33]. The energy closure ratio of ET across all sites was evaluated, and the results showed that the averaged energy closure ratio was $86.2 \%$, which is superior to the typical energy closure ratio of EC measurements (15-30\%) [34]. Thus, observed ET at the validation sites were considered reliable. Unaccounting for advection fluxes is one of the reasons for energy disclosure at EC sites. Another reason is that EC towers cannot capture the large eddies (with low frequency) associated with stationary secondary circulations that generate over tall canopies and heterogeneous landscapes [35-39].

2.2.3. Regional Climate Data. Climate data, including daily precipitation, temperature, air humidity, sunshine duration, and wind speed, were obtained from the National Climate Center, China. At the time of study, there were 106 meteorological stations across the Loess Plateau. These stations' climate data were aggregated to the monthly timescale to match that of the ET data. When analyzing the domainaverage trend of these climate variables, we averaged them for the 106 stations.

2.2.4. Vegetation Index. Vegetation indices are radiometric measures of photosynthetically active radiation absorbed by chlorophyll in the green leaves of vegetation canopies and are therefore good surrogate measures of the physiologically functioning surface greenness level of a region. The latest version of the GIMMS NDVI (Global Inventory Modeling and Mapping Studies Normalized Difference Vegetation Index) dataset spans the period July 1981 to December 2013 and is termed NDVI3g (third-generation GIMMS NDVI from Advanced Very High Resolution Radiometer (AVHRR) sensors). The NDVI3g time series is an improved $8 \mathrm{~km}$ NDVI dataset produced from AVHRR instruments and can be downloaded from http://ecocast.arc.nasa.gov/data/pub/ gimms/. This study used gridded NDVI data over the Loess Plateau for the period of January 1982 to December 2013. During data preprocessing, we spliced the images, transformed the projection, and extracted the study area (the Loess Plateau). The horizontal resolution of NDVI was set to $1^{\circ} \times 1^{\circ}$, to match the horizontal resolution of the ET data simulated by CLM, with the grid values interpolated by linear averages of the surrounding area.

2.3. Validation of GLDAS ET Product. A mismatch existed between the scales of the simulated and measured ET, which could have introduced uncertainty in the results. To date, an efficient way to overcome this problem remains elusive. However, in situ ET data can provide a reference for the simulated ET [40]. Given this, the ET produced by GLDAS was validated using the ET observed by the eddy covariance system at four sites in the Loess Plateau. Figure 2 compares the monthly CLM-simulated and measured ET at the four sites. It can be seen that the simulated ET was highly consistent with the measured ET at the four validation sites. As shown in Table 2, the fitting coefficient was close to 1, the average coefficient of determination $\left(R^{2}\right)$ was about 0.87 , the average root-mean-square error was about $8.12 \mathrm{~mm}$, and the relative error was about $20.32 \%$. The precision of remote sensing methods for estimating regional ET is within the range of $15-30 \%$ [1]. CLM produced ET that achieved an upper-middle level of precision, indicating that the CLMsimulated ET was reliable for the Loess Plateau.

\section{Results and Discussion}

3.1. Trends of Annual, Decadal, and Seasonal ET. Figure 3(a) shows the time series of domain-average annual ET over the Loess Plateau. It can be seen that ET decreased from 1982 to 2013 over the Loess Plateau, at a rate of $0.78 \mathrm{~mm}$ year $^{-1}$. The decreasing trend was weak before 1998 and then accelerated after 1998. The accelerated decrease in ET after 1998 may be related to severe drought caused by strong El Niño events in 1998 [41] and the temperature increase slowing down [27]. Figure 3(b) shows the time series of the ratio of ET to precipitation, which also shows an obvious decreasing trend. The decreasing trend implies that ET decreased more sharply than precipitation during the study period; water recycling from the land surface to the atmosphere was becoming weaker, as was the regional water cycle.

In terms of the interdecadal characteristics of changes in ET over the Loess Plateau (Table 3), ET decreased by $4.1 \mathrm{~mm}$ from the 1980 s to the $1990 \mathrm{~s}$ and then decreased more 

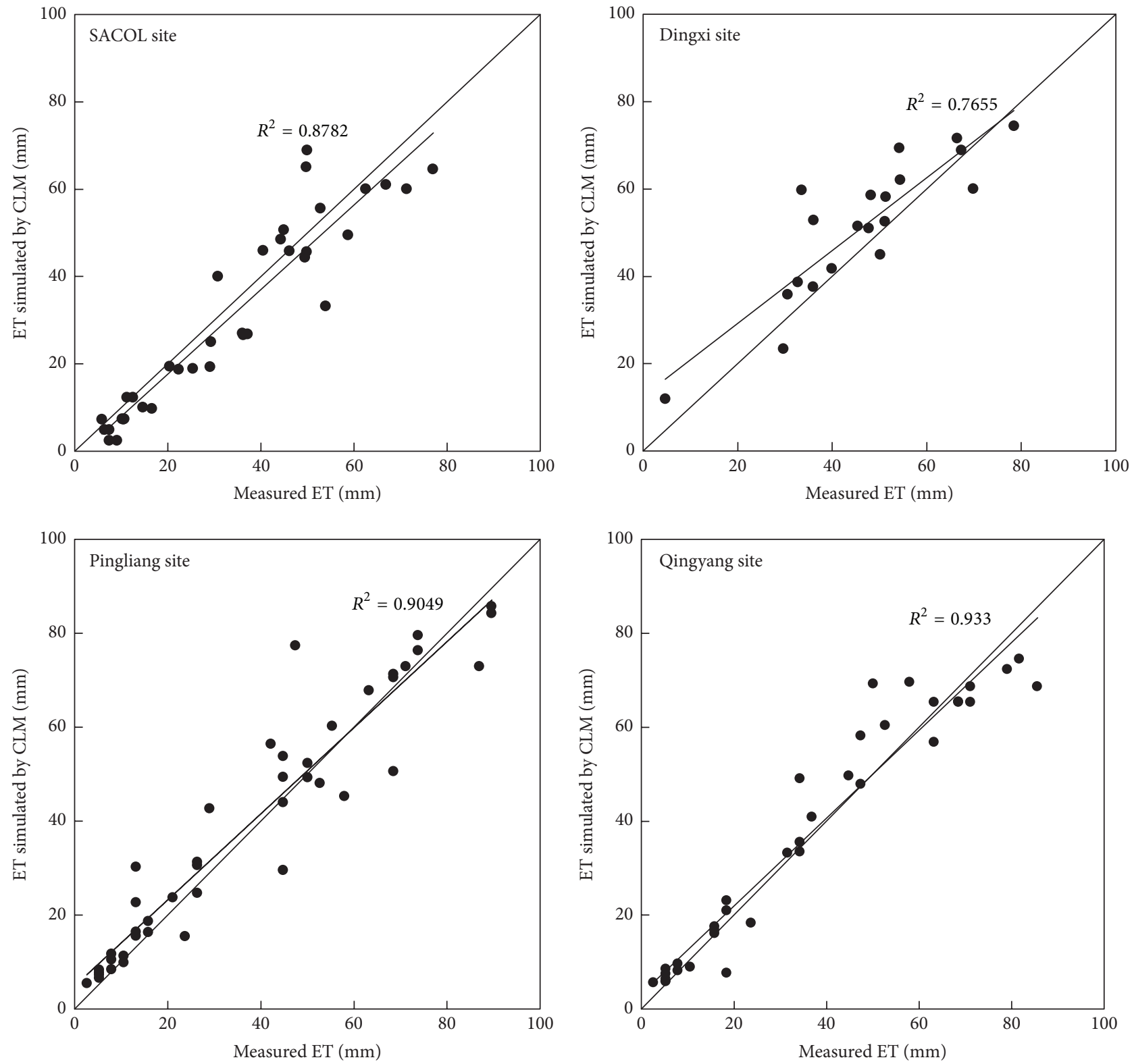

Figure 2: Comparison of simulated and observed ET at four sites (SACOL, Dingxi, Pingliang, and Qingyang) in the Loess Plateau.

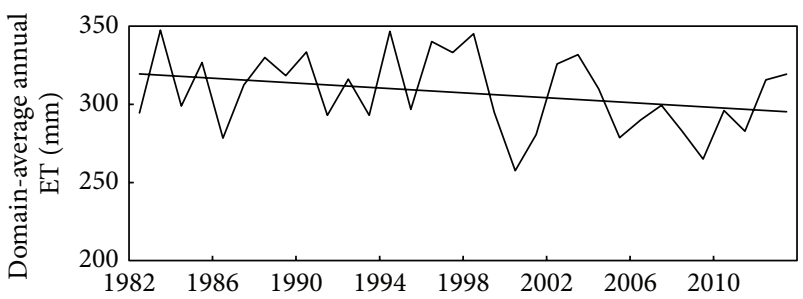

(a)

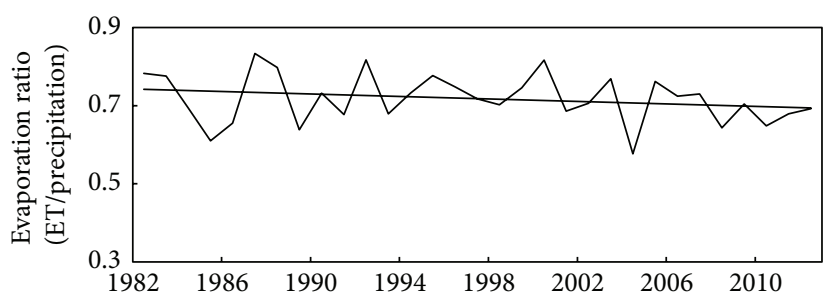

(b)

FIGURE 3: Trend of the (a) ET and (b) ET to precipitation ratio over the Loess Plateau during the period 1982-2013. 
TABLE 3: Interdecadal characteristics of ET over the Loess Plateau.

\begin{tabular}{lcc}
\hline Decade & Mean $(\mathrm{mm})$ & Standard deviation $(\mathrm{mm})$ \\
\hline $1980 \mathrm{~s}$ & 315.7 & 21.7 \\
$1990 \mathrm{~s}$ & 311.6 & 29.4 \\
$2000 \mathrm{~s}$ & 294.8 & 20.6 \\
\hline
\end{tabular}

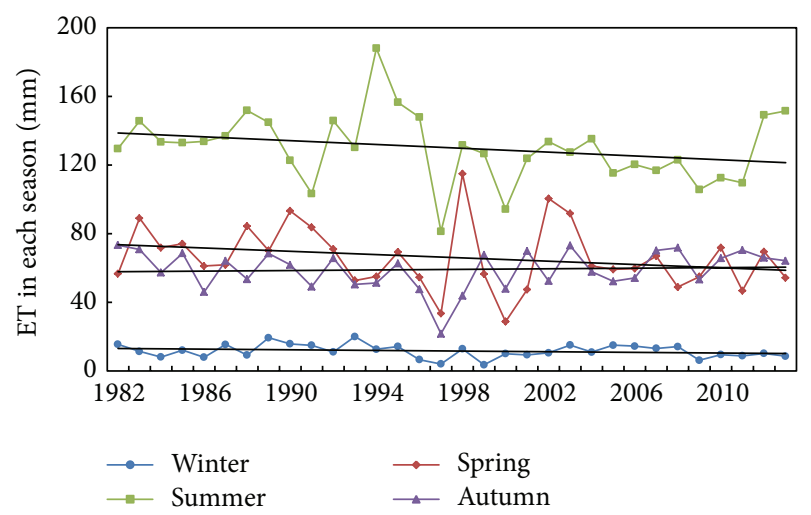

Figure 4: Trend of ET in each season over the Loess Plateau during 1982-2013.

rapidly from the 1990s to the 2000s (by $16.8 \mathrm{~mm}$ ). Besides, the standard deviation for the 1990s was much larger than that of the 1980s and 2000s, implying that ET fluctuated abnormally strongly in the 1990s, which could have caused disturbance of the water cycle leading to drought [42].

The ET trend in each season and their contribution to the overall ET trend were also investigated (Figure 4). For each year, the seasonal ET was calculated by summing the monthly ET within the separate seasons. It can be seen that ET decreased in all seasons except autumn. Summer had the largest magnitude, accounting for around half of the annual ET. ET also decreased most rapidly during summer, at a rate of $0.43 \mathrm{~mm}_{\text {year }}{ }^{-1}$. In spring, ET fluctuated strongly, especially around 1998, and had a relatively small rate of decrease. ET had a small mean and rate of decrease in winter, and in autumn, ET increased slightly but nonsignificantly. Overall, the summer trend dominated the declining ET trend over Loess Plateau.

3.2. Local ET Trend over the Loess Plateau. Although the domain-average ET decreased over the Loess Plateau during 1982-2013, it was possible that local ET trends may have differed due to the complicated topography and distinct features of local climate. Figure 5 shows the local ET trends over the Loess Plateau during the study period. As can be seen, ET decreased in most parts of the Loess Plateau, with the rate of decrease ranging from 1 to $3 \mathrm{~mm} y e a r^{-1}$. An ET increase was apparent in only a few parts of the Loess Plateau, with the rate of increase being less than $2 \mathrm{~mm}_{\text {year }}{ }^{-1}$ in most cases. This small increasing ET trend was dominated by the larger decreasing ET trend, meaning the domain-average ET showed an overall decreasing trend. The areas with an increasing ET trend were located in Tianshui District and the intersection of the Yellow River, Luo River, and Wei River, where there is a relatively high level of water availability.

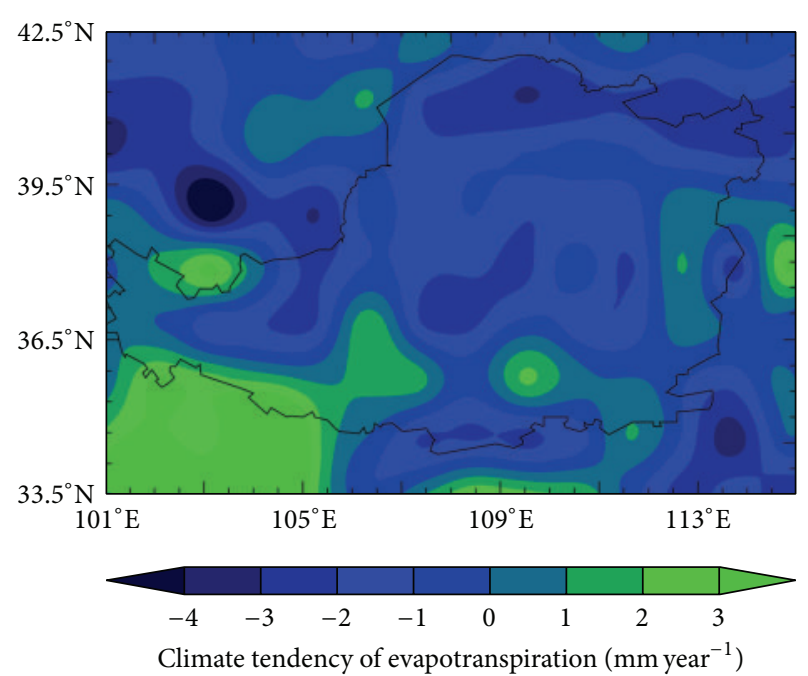

FIGURE 5: Distribution of the climate tendency of ET over the Loess Plateau.

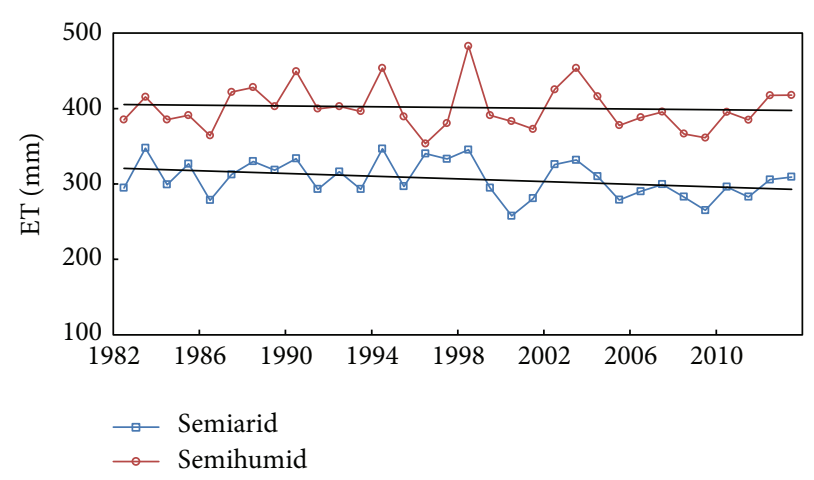

FIgURE 6: Trend of ET in the semiarid and semihumid areas of the Loess Plateau.

Figure 6 further breaks down the ET trend into that of the semiarid and that of semihumid region of the Loess Plateau. It can be seen that ET was much larger in the semihumid region than in the semiarid region. Furthermore, ET decreased more rapidly in the semiarid region than in the semihumid region, with their rates of decrease being $0.025 \mathrm{~mm}_{\text {year }}{ }^{-1}$ and $0.89 \mathrm{~mm}_{\text {year }}{ }^{-1}$, respectively. A larger availability of water slowed the rate of decrease in the semihumid region.

3.3. Attribution of the ET Trend. To elucidate the factors causing the decreasing ET trend, we examined the temporal evolution and trends of annual precipitation, air humidity, temperature, sunshine duration, wind speed, and vegetation conditions. Annual precipitation and air humidity showed an obvious decreasing trend during the study period (Figures $7(\mathrm{a})$ and $7(\mathrm{~b})$ ), meaning that water availability was decreasing over the Loess Plateau. The trend in sunshine duration was not significant (Figure 7(c)). Temperature and wind speed showed marked increasing trend, indicating that the evaporation potential was increasing (Figures $7(\mathrm{~d}$ ) and $7(\mathrm{e})$ ). NDVI also increased (Figure $7(\mathrm{f})$ ), which may have contributed to an increase in transpiration. These results indicate that 


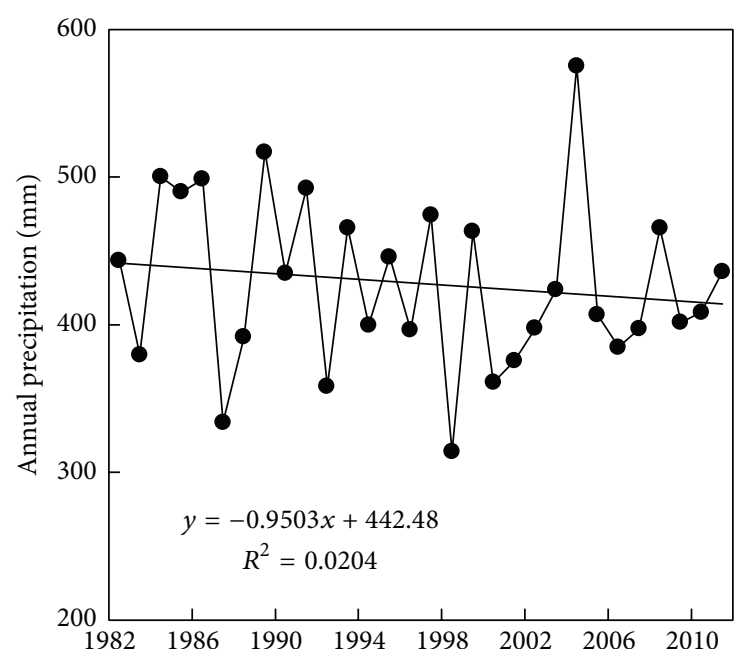

(a)

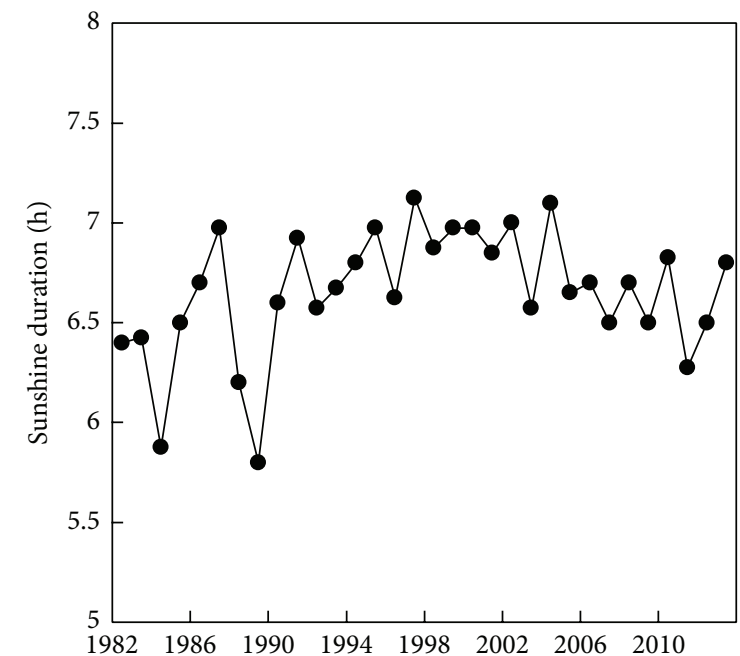

(c)

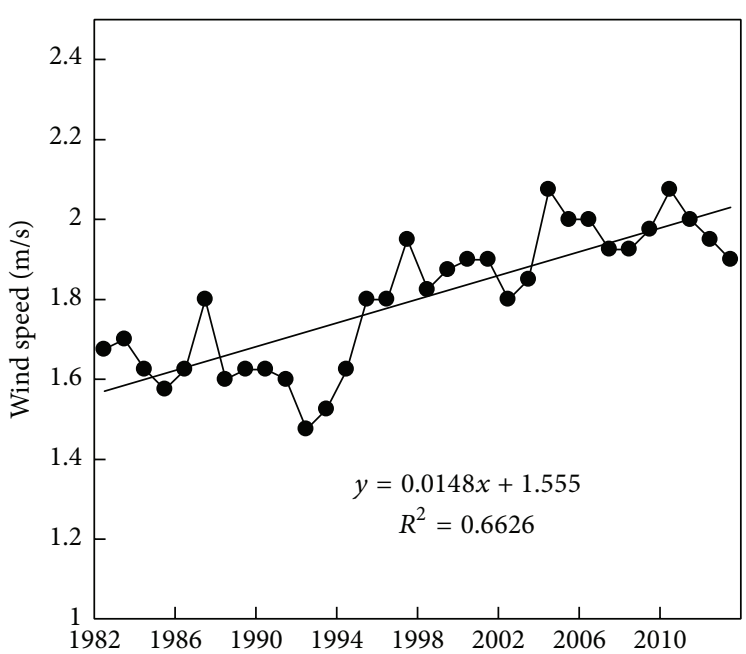

(e)

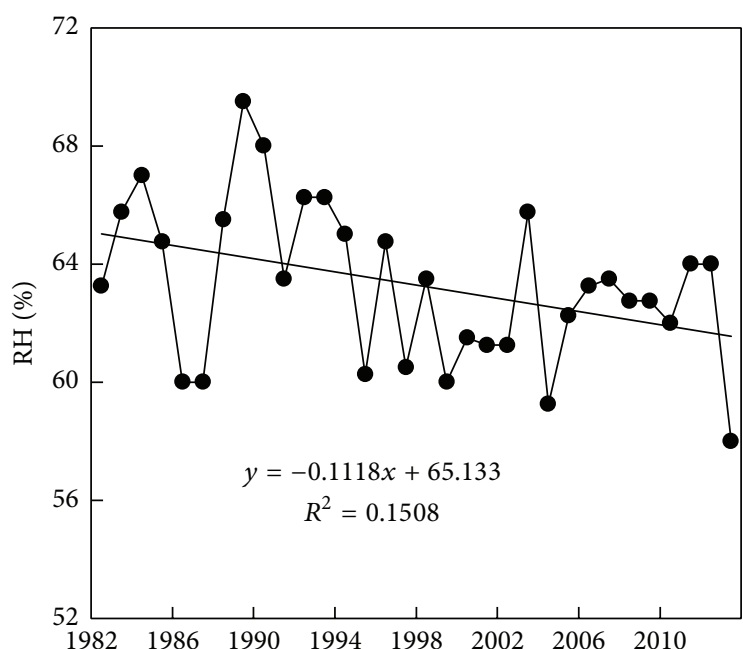

(b)

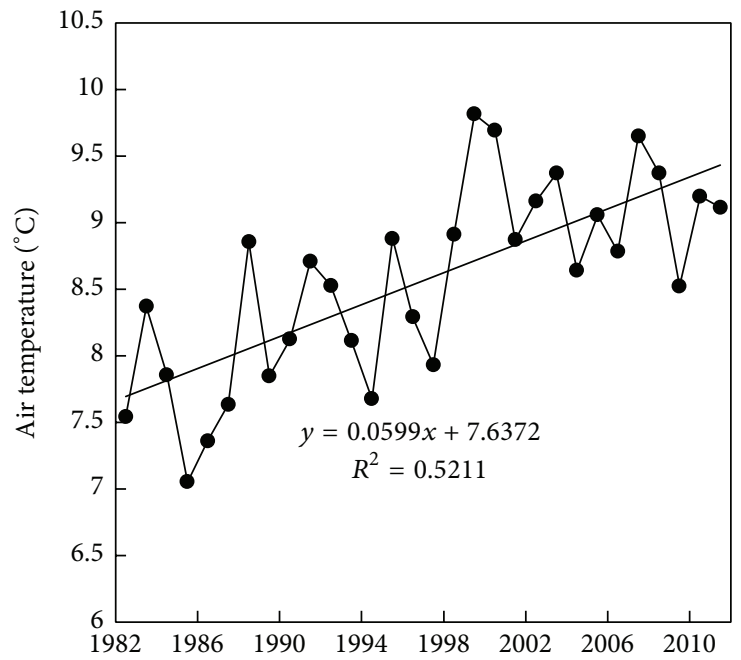

(d)

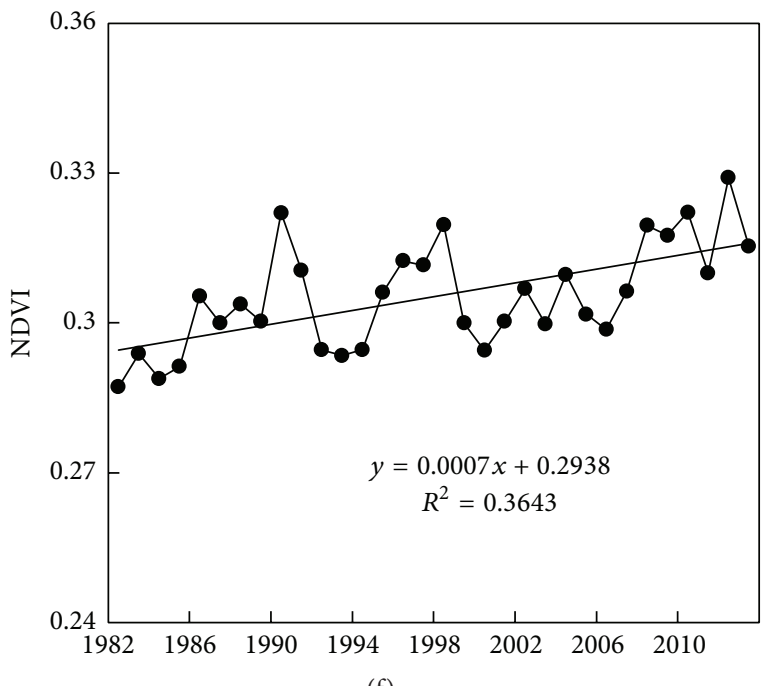

(f)

FIGURE 7: Trends of annual (a) precipitation, (b) air humidity, (c) sunshine duration, (d) air temperature, (e) wind speed, and (f) NDVI over the Loess Plateau. 


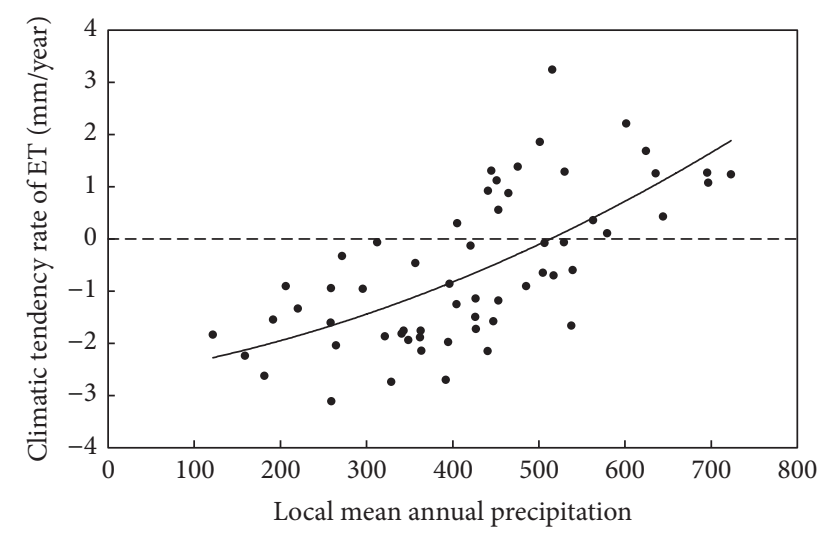

FIGURE 8: Relationship between the climate tendency rate of ET and local mean annual precipitation.

the declining trend in annual precipitation and air humidity caused the decreasing trend in ET, which outweighed the effects of increasing temperature, wind speed, and NDVI.

Increased potential ET $[24,25]$ and decreased actual ET imply that a complementary relationship between the two exists over the Loess Plateau. Similar research on different regions of China [17] showed that potential and actual ET were both controlled by available energy and both showed decreasing trends in humid and semihumid regions, while in arid and semiarid regions, potential ET was controlled by available energy and showed a decreasing trend, and actual ET was controlled by available water and showed an increasing trend. The Loess Plateau, however, shows an opposite ET trend compared to the arid and semiarid regions of China as a whole. The increasing ET trend in other arid and semiarid regions was attributed to increased precipitation, relative humidity, and cloud cover [43]. Our results showed that water availability, represented by precipitation and air humidity, was decreasing during the study period, which caused the decreasing trend of actual ET. In the study area, potential evapotranspiration (ET) is the upper limit of evapotranspiration when there is no water limit and represents the evaporative demand. Actual evapotranspiration is evapotranspiration mainly limited by the water supply of the area. Potential ET is higher than actual $\mathrm{ET}$; it means that the ET demand is higher than the actual ET, indicating that precipitation cannot meet the ET demand and all precipitation (except run-off) transforms into ET, resulting in a better correlation between actual ET and precipitation.

\subsection{Local ET Trends in Response to Mean Annual Precip-} itation. From the above analysis, it is apparent that water availability is the dominant factor controlling ET over the Loess Plateau. Therefore, the different local ET trends may be related to local water availability. Figure 8 shows the relationship between the climate tendency rate of local ET and mean annual precipitation. It can be seen that the climate tendency rate of local ET was closely related to local mean annual precipitation. The climate tendency rate of local ET changed from negative to positive when local mean annual precipitation increased. This implies that ET changed from being supply-limited to energy-limited due to increased water availability. The climate tendency rate was negative in supply-limited areas where local mean annual precipitation was less than $400 \mathrm{~mm}$, because water supply was decreasing in these areas; it could be negative or positive in the transition zone where local mean annual precipitation was within the range $400-600 \mathrm{~mm}$, and it was positive in energy-limited areas where local mean annual precipitation was greater than $600 \mathrm{~mm}$, because the ET potential was increasing and water availability was sufficient in these areas. In the semiarid region, local mean annual precipitation was less than $400 \mathrm{~mm}$, so the local climate tendency was negative and local ET showed a decreasing trend. In most of the semihumid region, local mean annual precipitation was within the range $400-600 \mathrm{~mm}$, so the local climate tendency was either negative or positive and local ET showed a decreasing or increasing trend in different areas. For the intersection areas of the Yellow River, Luo River, and Wei River, local mean annual precipitation was greater than $600 \mathrm{~mm}$, the local climate tendency rate was positive, and the local ET showed an increasing trend.

The strong solar radiation of the Loess Plateau means relatively high levels of available energy, and therefore the only limit for ET is the availability of water. An increase in water resources leads to changes in the climate tendency rate of ET from negative to positive, and this causes two opposing feedback mechanisms in the region. In areas with little precipitation (less than $400 \mathrm{~mm}$ ), the decreasing ET contributes less moisture to the atmosphere and decreases precipitation locally, further intensifying aridity. In areas with large quantities of precipitation (greater than $600 \mathrm{~mm}$ ), the increasing ET contributes more moisture to the atmosphere and increases precipitation locally, further intensifying humidity. These mechanisms are quite different from those in humid regions, where ET increases under low-precipitation conditions and decreases under high-precipitation conditions, due to available energy being reduced under high-precipitation conditions [44].

\section{Conclusion}

Based on CLM-simulated ET, the trend of ET was analyzed over the Loess Plateau from 1982 to 2013. The domainaverage ET decreased during the study period, at a rate of $0.78 \mathrm{~mm}$ year $^{-1}$. In particular, the decreasing trend accelerated after 1998, with ET decreasing more from the 1990s to 2000 s compared to the 1980 s to 1990 s. Stronger variation was also apparent for the 1990s, leading to an easier facilitation of drought. Apart from autumn, all seasons showed a decreasing trend, with summer dominating the interannual ET trend. Regionally, most of the Loess Plateau showed a decreasing ET trend, with only a few small areas showing an increasing trend (located in Tianshui District and the intersection areas of the Yellow River, Luo River, and Wei River). ET decreased more rapidly in the semiarid region than in the semihumid region. The declining trend of ET was attributed to declining precipitation and air humidity over the Loess Plateau during the study period. Local ET trends were closely 
related to local mean annual precipitation. Areas with mean annual precipitation less than $400 \mathrm{~mm}$ showed decreasing ET trends; areas with mean annual precipitation larger than $600 \mathrm{~mm}$ showed increasing ET trends; and areas with mean annual precipitation within the range $400-600 \mathrm{~mm}$ were transitional. Overall, the decreasing trend of ET indicates local water cycling weakened over the Loess Plateau during the study period, causing an energy partitioning preference toward sensible heat rather than latent heat, which accelerated surface warming and intensified land-atmosphere interactions.

\section{Competing Interests}

The authors declare that they have no competing interests.

\section{Acknowledgments}

The CLM-simulated ET data were provided by GLDAS. This work was jointly supported by the Major National Basic Research Program of China 2013CB430200 (2013CB430206), the National Science Foundation of China (31300376), and the Postdoctoral Science Foundation of China (2012M512044).

\section{References}

[1] K. Wang and R. E. Dickinson, "A review of global terrestrial evapotranspiration: observation, modeling, climatology, and climatic variability," Reviews of Geophysics, vol. 50, no. 2, Article ID RG2005, 2012.

[2] Y. Huang, D. Jiang, D. Zhuang, Y. Zhu, and J. Fu, "An improved approach for modeling spatial distribution of water use profita case study in Tuhai Majia Basin, China," Ecological Indicators, vol. 36, pp. 94-99, 2014.

[3] K. E. Trenberth, J. T. Fasullo, and J. Kiehl, "Earth's global energy budget," Bulletin of the American Meteorological Society, vol. 90, no. 3, pp. 311-323, 2009.

[4] P. J. Durack, S. E. Wijffels, and R. J. Matear, “Ocean salinities reveal strong global water cycle intensification during 1950 to 2000," Science, vol. 336, no. 6080, pp. 455-458, 2012.

[5] S. Cohen, A. Ianetz, and G. Stanhill, "Evaporative climate changes at Bet Dagan, Israel, 1964-1998," Agricultural and Forest Meteorology, vol. 111, no. 2, pp. 83-91, 2002.

[6] V. D. P. R. Da Silva, "On climate variability in Northeast of Brazil," Journal of Arid Environments, vol. 58, no. 4, pp. 575-596, 2004.

[7] D. G. C. Kirono, R. N. Jones, and H. A. Cleugh, "Pan-evaporation measurements and Morton-point potential evaporation estimates in Australia: are their trends the same?" International Journal of Climatology, vol. 29, no. 5, pp. 711-718, 2009.

[8] J. Q. Xu, S. Haginoya, K. Saito, and K. Motoya, "Surface heat balance and pan evaporation trends in Eastern Asia in the period 1971-2000," Hydrological Processes, vol. 19, no. 11, pp. 2161-2186, 2005.

[9] M. L. Roderick and G. D. Farquhar, "The cause of decreased pan evaporation over the past 50 years," Science, vol. 298, no. 5597, pp. 1410-1411, 2002.
[10] M. T. Hobbins, J. A. Ramírez, and T. C. Brown, "Trends in pan evaporation and actual evapotranspiration across the conterminous U.S.: paradoxical or complementary?" Geophysical Research Letters, vol. 31, no. 13, Article ID L13503, 2004.

[11] D. H. Burn and N. M. Hesch, "Trends in evaporation for the Canadian Prairies," Journal of Hydrology, vol. 336, no. 1-2, pp. 61-73, 2007.

[12] G. Papaioannou, G. Kitsara, and N. Melanitis, "Temporal analysis of hydrometeorological characteristics in Crete," in Proceedings of the Symposium on Water Resources Management: New Approaches and Technologies (EWRA '07), Chania, Greece, 2007.

[13] N. Chattopadhyay and M. Hulme, "Evaporation and potential evapotranspiration in India under conditions of recent and future climate change," Agricultural and Forest Meteorology, vol. 87, no. 1, pp. 55-73, 1997.

[14] T. Tebakari, J. Yoshitani, and C. Suvanpimol, "Time-space trend analysis in pan evaporation over Kingdom of Thailand," Journal of Hydrologic Engineering, vol. 10, no. 3, pp. 205-215, 2005.

[15] J. Asanuma and H. Kamimera, "Long-term trend of pan evaporation measurements in Japan and its relevance to the variability of the hydro-logical cycle," in Proceedings of the Symposium on Water Resource and its Variability in Asia, Meteorological Research Institute, Tsukuba, Japan, March 2004.

[16] H.-C. Zuo, Y. Bao, C.-J. Zhang, and Y.-Q. Hu, "An analytic and numerical study on the physical meaning of pan evaporation and its trend in recent 40 years," Chinese Journal of Geophysics, vol. 49, no. 3, pp. 680-688, 2006.

[17] B. Liu, Z. N. Xiao, and Z. G. Ma, "Relationship between pan evaporation and actual evaporation in different humid and arid regions of China," Plateau Meteorology, vol. 29, no. 3, pp. 629636, 2010.

[18] M. L. Roderick and G. D. Farquhar, "Changes in Australian pan evaporation from 1970 to 2002," International Journal of Climatology, vol. 24, no. 9, pp. 1077-1090, 2004.

[19] M. L. Roderick and G. D. Farquhar, "Changes in New Zealand pan evaporation since the 1970s," International Journal of Climatology, vol. 25, no. 15, pp. 2031-2039, 2005.

[20] W. Abtew, J. Obeysekera, and N. Iricanin, "Pan evaporation and potential evapotranspiration trends in South Florida," Hydrological Processes, vol. 25, no. 6, pp. 958-969, 2011.

[21] X. F. Qiu, Y. Zeng, and Q. L. Miu, "Calculating land surface actual evapotranspiration using Conventional meteorological data," Science in China, Series D-Earth Sciences, vol. 33, no. 3, pp. 281-288, 2004.

[22] A. J. Teuling, M. Hirschi, A. Ohmura et al., "A regional perspective on trends in continental evaporation," Geophysical Research Letters, vol. 36, no. 2, Article ID L02404, 2009.

[23] Y. J. Wang, B. Liu, and J. Q. Zhai, "Relationship between potential and actual evaporation in Yangtze River Basin," Advances in Climate Change Research, vol. 7, no. 6, pp. 393-399, 2011.

[24] X. Q. Xie and L. Wang, "Changes of potential evaporation in Northern China over the past 50 years," Journal of Nature Resources, vol. 22, no. 5, pp. 683-691, 2007.

[25] Z. Li, "Spatiotemporal variations in the reference crop evapotranspiration on the Loess Plateau during 1961-2009," Acta Ecologica Sinica, vol. 32, no. 13, pp. 4139-4145, 2012.

[26] S. Lin and Y. R. Wang, "Spatial-temporal evolution of precipitation in China loess plateau," Journal of Desert Research, vol. 27, no. 3, pp. 502-508, 2007. 
[27] Q. Zhang, J. Huang, L. Zhang, and L. Y. Zhang, "Warming and drying climate over Loess plateau area in China and its effect on land surface energy exchange," Acta Physica Sinica, vol. 62, no. 13, Article ID 019202, 2013.

[28] W. Wang, X. J. Wang, and P. Wang, "Assessing the applicability of GLDAS monthly precipitation data in China," Advances in Water Science, vol. 25, no. 6, pp. 769-778, 2014.

[29] J. Y. Zheng, Y. H. Yin, and B. Y. Li, "A new scheme for climate regionalization in China," Acta Geographica Sinica, vol. 65, no. 1, pp. 3-13, 2010.

[30] K. W. Oleson, Y. Dai, G. Bonan, M. Bosilovich, R. Dickson, and P. Dirmeyer, Technical Description of the Community Land Model (CLM), 2004.

[31] S. M. Liu, Z. W. Xu, Z. L. Zhu, Z. Z. Jia, and M. J. Zhu, "Measurements of evapotranspiration from eddy-covariance systems and large aperture scintillometers in the Hai River Basin, China," Journal of Hydrology, vol. 487, pp. 24-38, 2013.

[32] E. Falge, D. Baldocchi, R. Olson et al., "Gap filling strategies for long term energy flux data sets," Agricultural and Forest Meteorology, vol. 107, no. 1, pp. 71-77, 2001.

[33] S. M. Liu, Z. W. Xu, W. Z. Wang et al., "A comparison of eddycovariance and large aperture scintillometer measurements with respect to the energy balance closure problem," Hydrology and Earth System Sciences, vol. 15, no. 4, pp. 1291-1306, 2011.

[34] T. Foken, "The energy balance closure problem: an overview," Ecological Applications, vol. 18, no. 6, pp. 1351-1367, 2008.

[35] M. Mauder, T. Foken, R. Clement et al., "Quality control of CarboEurope flux data-part 2: inter-comparison of eddycovariance software," Biogeosciences, vol. 5, no. 2, pp. 451-462, 2008.

[36] T. Foken, R. Leuning, S. R. Oncley, M. Mauder, and M. Aubinet, "Corrections and data quality control," in Eddy Covariance., M. Aubinet, T. Vesala, and D. Papale, Eds., pp. 85-131, Springer, Berlin, Germany, 2012.

[37] J. Cuxart, L. Conangla, and M. A. Jiménez, "Evaluation of the surface energy budget equation with experimental data and the ECMWF model in the Ebro Valley," Journal of Geophysical Research D: Atmospheres, vol. 120, no. 3, pp. 1008-1022, 2015.

[38] J. Cuxart, B. Wrenger, D. Martínez-Villagrasa et al., "Estimation of the advection effects induced by surface heterogeneities in the surface energy budget," Atmospheric Chemistry and Physics Discussions, vol. 2016, pp. 1-16, 2016.

[39] Z. Gao, H. Liu, E. S. Russell, J. Huang, T. Foken, and S. P. Oncley, "Large eddies modulating flux convergence and divergence in a disturbed unstable atmospheric surface layer," Journal of Geophysical Research: Atmospheres, vol. 121, no. 4, pp. 1475-1492, 2016.

[40] Q. P. Liu, Y. C. Yang, H. Z. Tian, B. Zhang, and L. Gu, "Assessment of human impacts on vegetation in built-up areas in China based on AVHRR, MODIS and DMSP_OLS nighttime light data, 1992-2010," Chinese Geographical Science, vol. 24, no. 2, pp. 231-244, 2014.

[41] M. Jung, M. Reichstein, P. Ciais et al., "Recent decline in the global land evapotranspiration trend due to limited moisture supply," Nature, vol. 467, no. 7318, pp. 951-954, 2010.

[42] D. Li, "Assessing the impact of interannual variability of precipitation and potential evaporation on evapotranspiration," Advances in Water Resources, vol. 70, pp. 1-11, 2014.

[43] B. Liu, Z. Ma, J. Feng, and R. Wei, “The relationship between pan evaporation and actual evapotranspiration in Xinjiang since 1960," Acta Geographica Sinica, vol. 63, no. 11, pp. 1131-1139, 2008.
[44] Y. Song, Y. Ryu, and S. Jeon, "Interannual variability of regional evapotranspiration under precipitation extremes: a case study of the Youngsan River basin in Korea," Journal of Hydrology, vol. 519, pp. 3531-3540, 2014. 

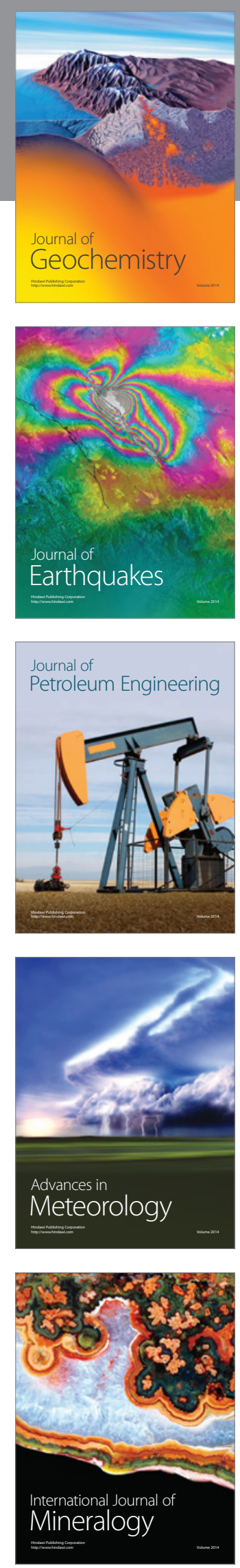
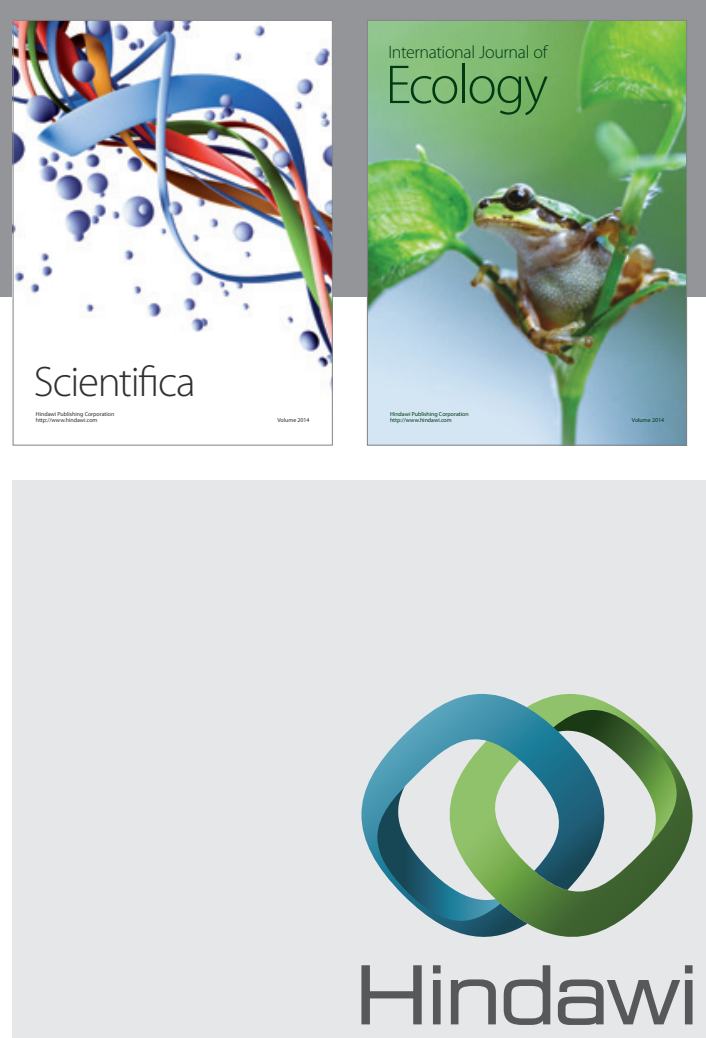

Submit your manuscripts at

http://www.hindawi.com
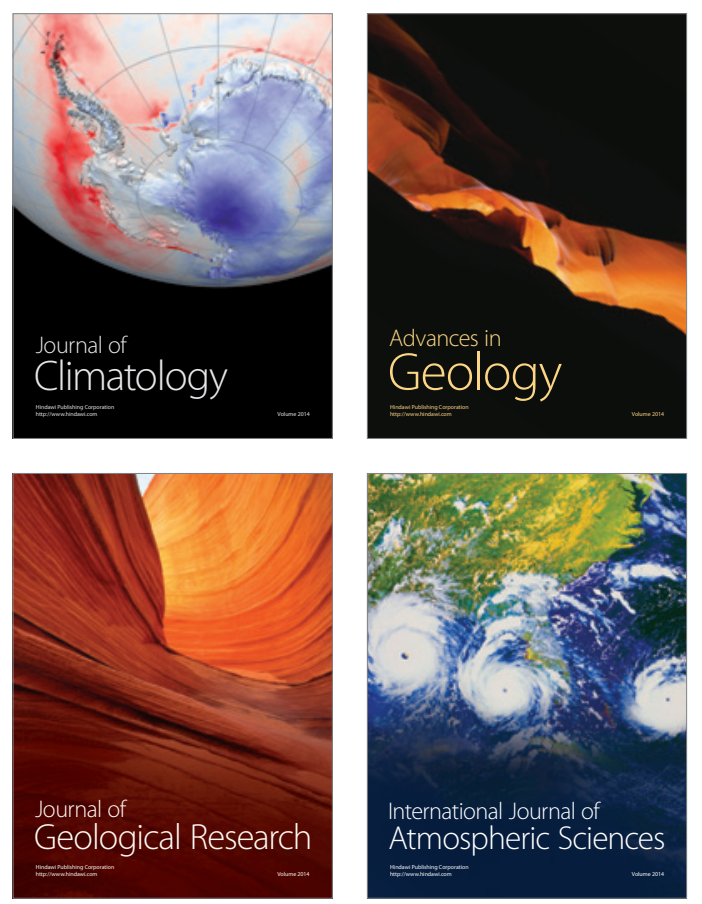

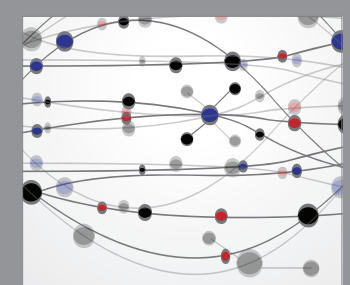

The Scientific

\section{World Journal}
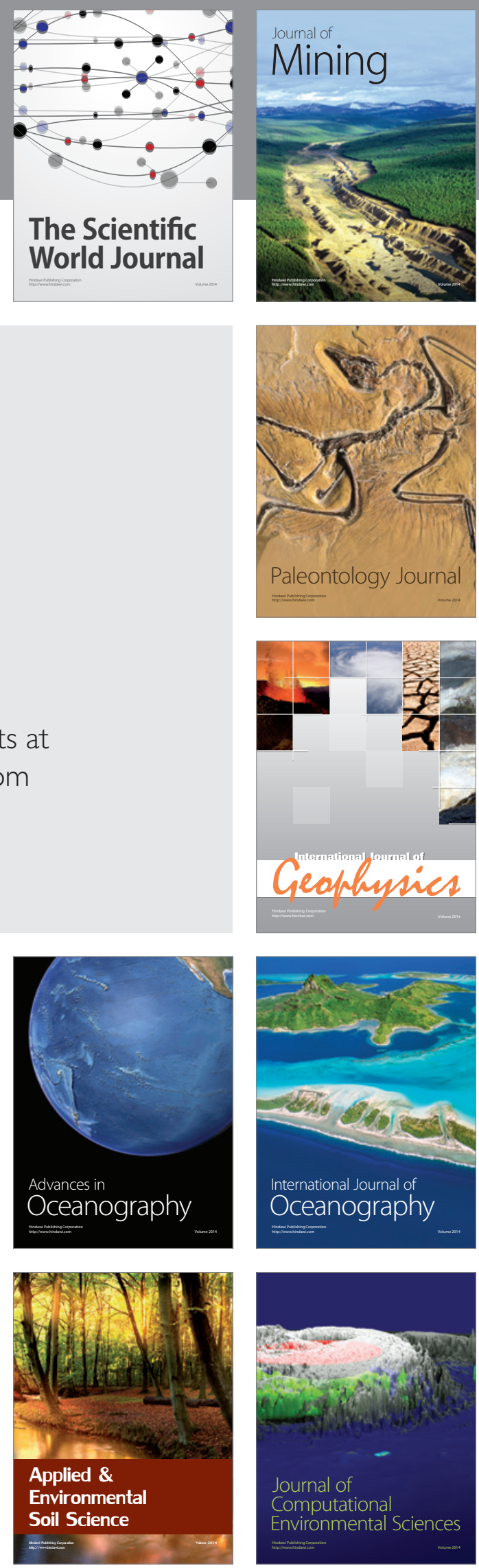